\title{
(2) OPEN ACCESS \\ Changing hospital organisational culture for improved patient outcomes: developing and implementing the leadership saves lives intervention
}

\author{
Erika Linnander (D) , ${ }^{1}$ Zahirah McNatt, ${ }^{2}$ Kasey Boehmer, ${ }^{3}$ Emily Cherlin, ${ }^{1}$ \\ Elizabeth Bradley, ${ }^{4}$ Leslie Curry (i) ${ }^{1}$
}

- Additional material is published online only. To view please visit the journal online (http://dx.doi.org/10.1136/ bmjqs-2019-010734).

${ }^{1} G$ lobal Health Leadership Initiative, Yale University School of Public Health, New Haven, Connecticut, USA

${ }^{2}$ University of Global Health Equity, Kigali, Rwanda

${ }^{3}$ Knowledge and Evaluation Research Unit, Mayo Clinic, Rochester, Minnesota, USA ${ }^{4}$ Vassar College, Poughkeepsie, New York, USA

\section{Correspondence to} Erika Linnander, Global Health Leadership Initiative, Yale University School of Public Health, New Haven, CT 06520, USA; erika.linnander@yale.edu

Received 8 December 2019 Revised 2 June 2020 Accepted 3 June 2020 Published Online Firs 16 July 2020
Check for updates

(C) Author(s) (or their employer(s)) 2021. Re-use permitted under CC BY-NC. No commercial re-use. See rights and permissions. Published by BMJ.

To cite: Linnander $\mathrm{E}$, McNatt Z, Boehmer K, et al. BMJ Qual Saf

2021:30:475-483

\begin{abstract}
Background Leadership Saves Lives (LSL) was a prospective, mixed methods intervention to promote positive change in organisational culture across 10 diverse hospitals in the USA and reduce mortality for patients with acute myocardial infarction (AMI). Despite the potential impact of complex interventions such as LSL, descriptions in the peer-reviewed literature often lack the detail required to allow adoption and adaptation of interventions or synthesis of evidence across studies. Accordingly, here we present the underlying design principles, overall approach to intervention design and core content of the intervention.

Methods of intervention development Hospitals were selected for participation from the membership of the Mayo Clinic Care Network using random sampling with a purposeful component. The intervention was designed based on the Assess, Innovate, Develop, Engage, Devolve model for diffusion of innovation, with attention to pressure testing of the intervention with user groups, creation of a think tank to develop a comprehensive assessment of the landscape, and early and continued engagement with strategically identified stakeholders in multiple arenas.
\end{abstract}

Results We provide in-depth descriptions of the design and delivery of the three intervention components (three annual meetings of all hospitals, four rounds of inhospital workshops and an online community), designed to equip a guiding coalition within each site to identify and address root causes of AMI mortality and improve organisational culture.

Conclusions This detailed practical description of the intervention may be useful for healthcare practitioners seeking to promote organisational culture change in their own contexts, researchers seeking to compare the results of the intervention with other leadership development and organisational culture change efforts, and healthcare professionals committed to understanding complex interventions across healthcare settings.

\section{BACKGROUND}

Hospital organisational culture is associated with patient outcomes ${ }^{1-4}$ including mortality after acute myocardial infarction (AMI); however, little is known about whether and how culture can be influenced across diverse hospital settings. Leadership Saves Lives (LSL) was a prospective, mixed methods intervention to promote positive change in organisational culture across 10 diverse hospitals in the USA ${ }^{5}$ and reduce mortality for patients with AMI. Results demonstrated substantial positive shifts in culture and reduced risk-standardised mortality rates (RSMR). Specifically, there were significant changes $(p<0.05)$ in culture particularly in learning environment $(p<0.001)$, senior management support $(\mathrm{p}<0.001)$ and psychological safety (qualitative data). Six of the 10 hospitals achieved substantial improvements in culture, and four made less progress. The six hospitals that demonstrated substantial shifts in culture also experienced significantly greater reductions in RSMR than the four hospitals that did not shift culture (reduced RSMR by 1.07 percentage points vs 0.23 percentage points; $p=0.03$ ).

These results were achieved through multidisciplinary, highly diverse leadership teams ('guiding coalitions'). ${ }^{6}$ As described originally by Kotter, ${ }^{7}$ a guiding coalition is a group of people committed to creating change in an organisation. Members are explicitly endorsed and empowered by senior leadership, and are diverse in multiple ways (eg, expertise, roles, levels of hierarchy). They are influential, trustworthy, willing and able to work outside traditional hierarchy, expectations and protocol. In hospitals that demonstrated positive changes, coalitions 
showed distinct patterns in membership diversity, authentic participation (eg, clear about expectations and performance of members) and capacity for management of the challenges of conflict, waning motivation and improvement fatigue. ${ }^{8}$ Furthermore, hospitals demonstrating culture change provided important insights into enhancing the role of pharmacists in care of patients with AMI, ${ }^{9}$ as well as opportunities to engage palliative care and improve advance care planning for patients with AMI. ${ }^{10}$

Despite the potential impact of complex interventions such as LSL, reports in the peer-reviewed literature often lack description of the intervention design process, and omit the detail required to allow for replication of the intervention for further testing, adoption and adaptation of the intervention for broader impact, or synthesis of evidence across studies. ${ }^{11-14}$ The protocol specifying the theoretical framework and central elements of the study's intervention design, as well as the study's evaluation methods, has been previously published, ${ }^{5}$ as have papers reporting validation of the organisational culture measure ${ }^{15}$ and results of the intervention on organisational culture and patient outcomes. ${ }^{6}$ However, specific elements of the development and delivery of the intervention were not described in detail in these previously published papers.

Accordingly, here we present the underlying design principles, overall approach to intervention design and core content of the intervention. Given the success of the intervention to improve organisational culture in ways associated with patient outcomes, ${ }^{6}$ a clear description of the method of intervention adds to the literature on quality improvement and healthcare leadership. This in-depth description may be useful for healthcare practitioners seeking to promote organisational culture change in their own contexts, researchers seeking to compare the results of the intervention with other leadership development and organisational culture change efforts, and healthcare professionals interested into understanding complex interventions across healthcare settings.

\section{INTERVENTION GOAL AND SETTING}

As previously described, the LSL intervention was designed to foster reductions in AMI mortality by supporting the implementation of evidence-based strategies and fostering improvements in domains of organisational culture related to hospital performance. ${ }^{15616}$ Hospitals were selected for participation from the membership of the Mayo Clinic Care Network (MCCN), a national group of hospitals and health systems committed to quality improvement through collaboration.

\section{GUIDING PRINCIPLES FOR INTERVENTION DESIGN}

The intervention was informed by the Assess, Innovate, Develop, Engage, Devolve (AIDED) model of diffusion, ${ }^{17}$ which highlights the importance of obtaining a precise understanding of the receptivity of 'user groups' (eg, hospitals) to the innovation, awareness of the landscape including financial and regulatory levers, and deep engagement of key stakeholders including boundary spanners ${ }^{18}$ (eg, individuals within an organisation who are able to cross various structural or cultural boundaries in order to share knowledge or influence dynamics). To operationalise these principles during the intervention design phase, we carried out three activities in this sequence, with iteration between the think tank and pressure testing in order to address ongoing feedback: (1) creation of a 'think tank' of academic experts to develop a comprehensive assessment of the relevant scientific, financial and regulatory landscape, (2) 'pressure testing' of the intervention with user groups, and (3) early and continued engagement with influential stakeholders and boundary spanners in multiple arenas. Each of these activities is described in more detail below.

We assembled a 'think tank' at the launch of the project and included a wide range of diverse academics as standing members, including expertise in organisational theory, economics, healthcare management, medicine, public health, social work, health services research and others. Additional ad hoc experts were invited to present on specific topics (such as options for the web-based platform described below). The group met in four 2-hour sessions over a 4-month period to foster dynamic, critical and creative discussion on intervention design, and to ensure all aspects of the intervention were grounded in the latest and most robust scientific evidence and knowledge of the broader context of AMI care delivery (such as trends in RSMRs and reimbursement issues). In each session, a discussion lead would compile the most relevant scientific and practice-based evidence on a given topic, create and share a two to three-page summary with the group and foster conversation and synthesis relevant to LSL intervention design. Focal topics were highly diverse, ranging from organisational culture change to AMI mortality rates, to team-based leadership and modes of intervention delivery such as remote support and 'dose' of exposure (see box 1).

'Pressure testing' involved piloting specific components of the intervention with the aim of obtaining critical feedback on design assumptions and plans, particularly from the 'end user' perspective. We developed a draft plan for the intervention based on our prior experience in leadership development programming ${ }^{19}$ as well as relevant empirical literature, proposing three main components (described further below): annual convenings of all hospitals, on-site workshops and remote support. We conducted pressure tests with three panels: (1) experts in cardiology attending the American College of Cardiology Scientific Meeting in Washington DC, (2) diverse clinicians and administrators working in cardiovascular care at 
Box 1 Think tank topics

Intervention content

- Organisational culture change.

- Building physician leadership capacity.

- Interventions to improve relational coordinationwhat has worked?

- Team-based leadership: How is it described in the literature? How do we want to conceptualise it for use in the intervention? How do we balance the need for individual coaching or development?

What is culture? How is it defined?

\section{Intervention mode of delivery}

- Remote support (eg, online communities, webinars): What works and what does not? (healthcare and nonhealthcare applications).

- What dose might be optimal for exposure to intervention? How do we know? (eg, from education literature).

- How do we balance being external experts while establishing hospital ownership and organic implementation of strategies? (eg, from knowledge transfer literature).

- Introducing the intervention to hospitals: How have other efforts described themselves? How might we differentiate (or not!)? What early steps in engagement are critical?

\section{Environment}

- 'Devolve' in Assess, Innovate, Develop, Engage, Devolve (AIDED): What can we learn from biological mechanisms that can help us maximise likelihood of spread to network hospitals?

a large health system in New England, and (3) diverse clinicians and administrators working in cardiovascular care from a large hospital system on Long Island, NY. These sessions were $2-4$ hours in duration. We asked participants for their thoughts on a wide range of topics including how best to pitch the study to hospital leaders, feasibility of specific features such as the workshops and comfort with the research aspects such as being observed (see box 2). The sessions generated highly useful information about how to tailor the intervention activities to fit the hospital environment. We made several substantive modifications to the intervention including the plan to have flexible modules and schedule formats to accommodate workflow at each hospital, and strategies for gaining support from intervention participants. Illustrative feedback from a pressure testing session is presented in box 3 .

Engagement. Engagement of stakeholders began very early in the design phase, when we reached out to MCCN to partner in the project. We hypothesised that MCCN member hospitals would be likely to be receptive to the intervention, to the extent that membership in MCCN represented significant prioritisation of and investment in quality improvement. We also were aware that working with MCCN would provide us direct access to hospitals' clinical and administrative leadership. We used random sampling with a purposeful component ${ }^{20}$ to select a sample of 10 hospitals from within MCCN. After randomising the list of hospitals $(n=18)$, beginning from the top, we selected hospitals to create a sample diverse in teaching status and geographic region. We approached the first 10 hospitals to determine receptivity; one declined due to reorganisation, and one declined as a competing initiative was underway. We replaced these two hospitals with similar receptive sites. We approached the senior leadership team to obtain explicit support; engagement involved paying close attention to how to align with their interests, using deliberate framing and language, anticipating and responding promptly to any requests and cultivating trusting relationships. Recruitment of each hospital followed these steps. First, the project liaison from MCCN reached out to chief executive officers (CEO) to explore high-level interest in the study, and if the CEO was receptive, arranged an invitational meeting with the LSL study team leads (principal investigator (LC), project director (ZMN) and intervention lead (EL)). A succinct overview of the project was forwarded to the hospital as background material for the call (online supplementary file 1). Second, we held invitational meetings via telephone that included senior executives as well as, at the discretion of each hospital, lead cardiologists, quality improvement experts and risk management. In these meetings, the rationale and objectives for the intervention were briefly described, as well as the investment required

\section{Box 2 Pressure test questions}

1. The pitch: How would you pitch a project like this to a group of senior managers in hospitals? to clinical teams? What would convince you to enrol your hospital?

2. Realities of participation: Is this something you would want your hospital to participate in? Why/why not?

3. Level of interest: Which aspects of the project do you find most appealing or exciting? What barriers to participation do you see? How could those be overcome?

4. Hospital workshops: How feasible will it be for hospitals to find time for a workshop twice a year? (full day of content, could be spread over 2-3 days if needed). What are your thoughts on workshop content? What would you want to learn if you were a participant?

5. Qualitative observations by the research team: Would you have any concerns about being observed in meetings? What do you think about other staff? How can our team overcome those concerns? 


\section{Box 3 Pressure test illustrative feedback}

What is going to sell this intervention to hospitals?

- The chance it will work.

- Knowing the market share.

- The Affordable Care Act changes in reimbursements.

- Need to understand what bundles the hospital is involved with.

- Value-added purchasing.

- The ability to address the real problems in the specific hospital.

- Role of outside facilitator-not there to critique physicians care, and so on.

- Free process improvement.

- Learning from peers (but want peers to be actual peers or be better than them).

\section{Concerns shared about qualitative work}

- Need to think through how deep the Leadership Saves Lives team will be able to see into the organisation.

- How will hospitals feel about shadowing clinicians when involved with direct patient care.

- Clinicians and people in hospital will not always be able to differentiate between the intervention and research team-people may be annoyed at answering or explaining the same thing twice to people they see as representing the organisation leading the study.

- Consider patient confidentiality rules if on rounds/ quality improvement meetings/quality improvement or research.

\section{In order to work}

- Need both bottom-up and top-down buy-in.

- Complements existing management programme-not replacing program (ie, Six Sigma).

\section{Other comments}

- Stay mindful of mid-level practitioners (physician assistants, advanced practice nurses).

- Have a poster session at the annual meetings.

- Ask about organisational pride.

- Need to be transparent that you are also benefiting from this and this is research.

What about the Hawthorne effect?

- Should offer a 'toolbox' to hospitals with guidelines and education or at least offer more than just what to do but HOW to do it.

- What about confounding, participation bias, and so on?

for participation (protecting time of staff time for involvement on the guiding coalition and the research components, commitment to improvement projects, access to hospital leadership). Because the discussions were driven by the hospitals, the majority of the meetings consisted of the research team responding to questions and concerns from the hospital leadership.
In some instances, follow-up materials or additional meetings were requested and provided. For example, several hospitals felt they would need a concise 'FAQ' (Frequently Asked Questions) sheet to describe the study to their board of directors and other stakeholders. We developed, piloted and revised an FAQ document to support them in their communications. Finally, once hospitals agreed to participate in the study, the CEO provided a signed letter of commitment to participate in the project in order to convey political will and support for the intervention (online supplementary file 2). Of note, we did not require any type of binding contract for participation in the study, and hospitals were advised that they could withdraw from the study at any time. We maintained direct communication with the CEO at least annually throughout the study, providing updates about study progress and accomplishments. All 10 hospitals continued participation throughout the intervention period.

\section{INTERVENTION DESCRIPTION}

The final design of the intervention included three core $^{21}$ components: (1) a series of three annual convenings attended by four key members of each guiding coalition; (2) a series of four 1-day workshops on-site with the full coalition at each hospital; and (3) a web-based platform that allowed hospitals to share experiences and served as a repository for programme resources (figure 1). The intervention period was 24 months in duration; we recognised this was ambitious, as prior literature suggests that measurable changes in organisational culture typically require up to a decade to observe. ${ }^{22}$ As part of the evaluation of the impact of the intervention on organisational culture and practices associated with care for patients with AMI, we administered a web-based survey to guiding coalition members. ${ }^{6}$ Results (both hospital-specific and intervention-wide averages) were reported back to participants as real-time feedback for discussion during the intervention (this feedback is described further below).

Component 1: Annual convenings occurred every summer for a 3-day period in a major city convenient to the participants from the 10 hospitals. Each hospital was asked to send four senior champions for the project representing administrative, physician, nurse and quality improvement leadership. Travel costs were covered by the project grant, and time for participation was committed by the participating hospitals. The convenings were designed to cultivate a community of peers that could rely on one another for advice and mentoring on culture change and quality improvement. Sessions included educational content, cross-hospital round tables and presentations, and opportunities for networking and healthy competition. The sequence of convenings was intentionally designed to move the hospitals along a progression from understanding and 'buying in' to the evidence base to sharing 


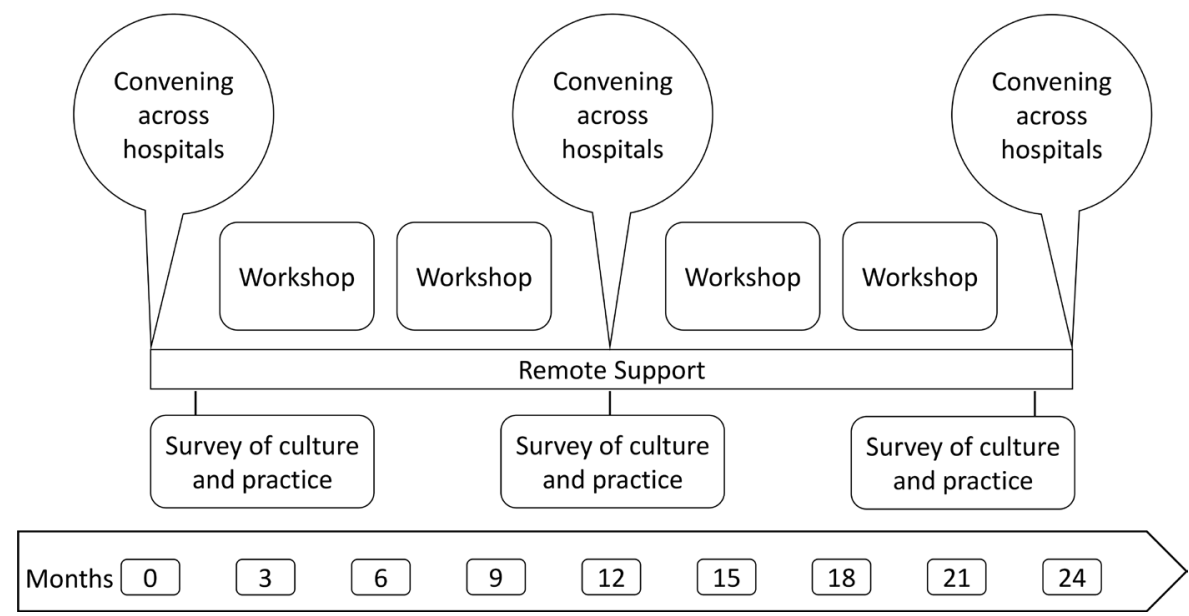

Figure 1 Intervention components

implementation challenges and successes as they worked through the intervention period. In the first convening, hospitals were introduced to the concept of organisational culture and the evidence regarding building effective teams to lead improvements. Each hospital also prepared to establish a guiding coalition ${ }^{7}$ tasked with reducing AMI mortality rates. Hospitals were given guidance around coalition membership and structure, followed by facilitated work sessions to tailor the approach to their unique context. They were asked to engage approximately 15 key staff involved in care of patients with AMI, including staff from multiple departments (ie, cardiology, emergency medicine, pharmacy, quality improvement, cardiac rehabilitation), professions (ie, physicians, nurses, technologists, administrators, physician assistants) and levels of the organisation (from senior executives to front-line staff). They determined how best to organise themselves, and met as frequently as once per month or once per quarter. Some coalitions developed subgroups focused on specific tasks while others functioned best as a full group.

In the second convening, hospitals had been engaged in the intervention for almost 12 months. Hospitals delivered formal presentations to each other, describing progress over the past year, highlighting challenges and successes. In addition, a series of facilitated breakout sessions focused on each of the five evidence-based strategies, ${ }^{16}$ summarising the latest empirical evidence on each and allowing participants to share and brainstorm approaches to implementation in their particular settings.

The third and final convening focused on in-depth, practical discussions across institutions. Hospitals again reported on their progress towards reducing AMI mortality and associated lessons learnt. They also packaged and shared the tools and approaches they had created or adapted in efforts to reduce AMI mortality. In years 2 and 3, hospitals also voted for the 'STAR' (Striving to Achieve the Remarkable) peer hospital that best exemplified commitment to the objectives of the LSL learning community, as an acknowledgement of efforts to both improve patient care and to share challenges and lessons learnt.

At the end of each convening, participants provided evaluative feedback via paper-based survey, including the extent to which they believed the learning objectives had been met, reflections on aspects of the convening that were most valuable and suggestions for improvement. Agendas for each annual convening are included as online supplementary file 3 .

Component 2: On-site workshops were intended to build leadership capacity within the guiding coalition and to catalyse progress towards improved organisational culture and uptake of the evidence-based strategies. Each workshop included approximately one full day of content, which could be broken up over multiple days depending on the preferences of the guiding coalition. The core curriculum for the workshops addressed both how to work (building an effective organisational culture) and what to work on (strategic problem solving ${ }^{23}$ to address root causes of mortality). In the first workshop, the primary objectives were to orient the guiding coalition members to the intervention and the evidence base, promote reflection on baseline measures of culture and practice, identify a problem statement and objective on which the group would focus their root cause analysis process and build effective working relationships and processes among coalition members, including representation and role clarity, ${ }^{24}$ decision-making ${ }^{25}$ and accountability. ${ }^{26}$

Between workshops, the coalitions were tasked with making and measuring progress towards addressing their priority root causes of AMI mortality using a strategic problem-solving approach. ${ }^{23}$ Primary root causes included, for example: inconsistent practices for preparation of patients arriving by air, and lack of systems to promote reliable identification or systematic care for patients with non-ST-elevation myocardial 
Table 1 Illustrative hospital project using strategic problem solving

\begin{tabular}{lll}
\hline Step & Description & Example \\
\hline Problem & All coalitions began with the same problem statement. & AMI mortality is too high. \\
Objective & $\begin{array}{l}\text { Coalitions then generated a mirroring objective that } \\
\text { was meaningful and measurable within their operating } \\
\text { context. }\end{array}$ & $\begin{array}{l}\text { Reduce unadjusted 30-day AMI mortality for all payer classifications by 3\% } \\
\text { from Fiscal Year 2014 baseline (6.69\%) by 31 December 2015. }\end{array}$ \\
$\begin{array}{lll}\text { Root cause } \\
\text { analysis }\end{array}$ & $\begin{array}{l}\text { Coalitions used multiple sources of data to identify and } \\
\text { prioritise root causes of AMI mortality in their context. }\end{array}$ & $\begin{array}{l}\text { Lack of standardisation of care, complex patient population with multiple } \\
\text { comorbidities, inconsistent transitions in care. }\end{array}$ \\
$\begin{array}{l}\text { Strategy } \\
\text { development }\end{array}$ & $\begin{array}{l}\text { Coalitions adapted evidence-based strategies and } \\
\text { generated novel strategies, tailored to address their } \\
\text { prioritised root causes. }\end{array}$ & $\begin{array}{l}\text { Structured form for pharmacy rounding on patients and review discharge } \\
\text { medications; introduction of real-time risk stratification using two tools; } \\
\text { creation of an AMI follow-up clinic. }\end{array}$ \\
Results & $\begin{array}{l}\text { Coalitions created evaluation plans to match their } \\
\text { strategies and evaluate progress towards their SMART } \\
\text { objective. }\end{array}$ & $\begin{array}{l}\text { Increase in number of pharmacist interventions; improved reliability of risk } \\
\text { stratification; decrease in proportion of patients lost to follow-up; decrease in } \\
\text { unadjusted mortality from 6.7\% to 2.7\%. }\end{array}$ \\
\hline
\end{tabular}

AMI, acute myocardial infarction.

infarction. Table 1 provides an illustrative example of a hospital project.

At subsequent workshops, members reported out on their progress on strategy implementation and AMI mortality rates, with the goal of addressing implementation challenges and further developing their individual and group leadership capacity. Facilitators shared feedback on uptake of evidence-based practices, changes in organisational culture (based on surveys administered at three time points during the intervention) and hospital-specific measures of AMI mortality (see online supplementary file 4). Of note, each hospital developed a measure of AMI mortality that was feasible for them to measure in a timely way to drive improvement. Measures varied in terms of hospitals' decision to conduct risk adjustment, track in-hospital versus 30-day mortality and include Centers for Medicare \& Medicaid Services (CMS) patients or a broader patient population. Additional core workshop 2 content included diagnosing and shaping organisational culture, engaging conflict productively, ${ }^{27}$ using levels of analysis to diagnose organisational challenges ${ }^{28} 29$ and working with power and hierarchy. ${ }^{30} 31$ In workshop 3, coalitions focused on addressing barriers in implementation of their strategic problem-solving projects and organisational culture change efforts followed by additional learning on adaptive leadership in complex systems. In workshop 4 , coalitions used the AIDED model ${ }^{17}$ to both promote uptake and sustainability of their strategic problem-solving project results and to inform potential application of LSL ways of working to other complex challenges in the hospital.

All coalitions covered the full curriculum over the course of the four in-hospital workshops. Workshop content was tailored to the local context in each hospital by adjusting the timing of these modules to meet teams' most pressing needs, adapting the specific examples and experiential learning exercises used in each module, articulating linkages between these content areas and ongoing work in each hospital and encouraging each hospital to focus on root causes of AMI mortality that are most salient in their environment (as opposed to just picking one of the five evidence-based practices). At the end of each workshop, participants provided evaluative feedback via paper-based survey, including the extent to which they believed the learning objectives had been met, reflections on aspects of the workshops that were most valuable and suggestions for improvement.

The workshop facilitation team included expert facilitators from across the USA, with backgrounds in organisational development, leadership education and quality improvement. Facilitators worked in teams of two, sometimes joined by a third facilitator with a clinical background relevant to the priority challenges of the guiding coalition. To allow for facilitators to become deeply familiar with each hospital, as well as for continuity of relationships with members of the guiding coalitions, a lead facilitator was assigned to each hospital for the duration of the intervention. The secondary facilitator role was filled based on scheduling availability.

Prior to each round of workshops, facilitators came together for a full-day, in-person orientation to the workshop objectives, design, and teaching and learning materials. To promote standardisation of the intervention across sites while allowing for adaptation to local context, facilitators referred to a fidelity checklist for each workshop (online supplementary file 5). These checklists enumerated the outputs or milestones that each coalition was expected to reach in the workshop, and served as a record in case sessions were missed due to scheduling challenges or remedial work. During the delivery of each round of workshops, the full group of facilitators met two to three times via teleconference to debrief on the workshops delivered so far and adjust as needed for upcoming hospital site visits. At the end of each workshop, the lead facilitator prepared a structured written summary of decisions and action items for report back to the guiding coalition and to the full facilitation team as a summary of progress. Each 
individual facilitator also completed the fidelity checklist based on their experiences of the workshop.

Component 3: Web-based information-sharing platform. The online platform had two primary functions. First, to serve as an accessible, up-to-date repository of LSL materials and references, including workshop/ forum materials as well as evidence and tools relevant to each of the practices for reducing AMI mortality. Second, to support direct communication across hospital teams and between hospitals and the research team for sharing of successes, barriers and project updates. We researched four possible platforms, and selected a password-protected platform called Basecamp based on several priority features: (1) ease of use, (2) integration with email communication, and (3) ability to create project spaces with discrete access. One space was dedicated for annual convenings, and included a repository for presentations, round-table summaries, agendas and contact lists. This space was open to all members of all 10 guiding coalitions. A second space housed each of the evidence-based practices and included evidence briefs, peer-reviewed papers and other reference materials. This space was also open to all members of all 10 coalitions. A third set of limited-membership spaces was created, one for each guiding coalition, that included workshop materials including agendas, presentations and summary/ action items. On a weekly basis, a member of the research team sent an update to all LSL participants to share tools and new scientific evidence related to AMI mortality, address questions from participants and promote sharing of experiences across participating hospitals. For example, some updates included resources related to a specific strategy (such as online sites for emergency medical services training and e-learning), while others were curated responses to participant questions that we compiled with input from national experts. Between weekly announcements, the site was monitored continuously, and senior members of the research team addressed participant questions within 1 day of posting. In many cases, questions posed by participants were addressed directly by other participants, promoting peer-to-peer connections and learning. The level of participation in Basecamp was uneven and sporadic; it was the component of the intervention that received the most mixed feedback.

These three components of the intervention were considered core ${ }^{21}$ to the intervention; however, within them, there were opportunities for adaptation to fit the needs and context of each hospital. First, in terms of workshops, the content and duration were core, while the timing and format were adaptable (eg, 1 day or 2 half days, morning/evening). Second, in terms of convenings, the objectives and broad content were core, while specific sessions were tailored to hospital innovations and led by participants. Finally, Basecamp was a core communication platform, while questions and content were participant driven.
LESSONS LEARNT

We hypothesise that several defining features of the intervention may have contributed to its effectiveness. First, expert facilitation from a well-regarded academic partner allowed for coalitions to address tensions, challenges and various impediments with the benefit of a credible, external, neutral party. Second, the intervention was not purely focused on the technical implementation of evidence-based strategies in AMI care, but rather focused primarily on the relational aspects of work within the coalitions and the integration of the evidence-based practices into broader strategic problem-solving efforts. Third, the combination of externally facilitated workshops and cross-hospital practical experiences of peers allowed hospitals to integrate the latest science, as well as to develop organic solutions. Such solutions were highly credible because they were developed by peers, a principle core to positive deviance. ${ }^{32} 33$ Fourth, the intervention required protected time for each coalition member to participate fully. Participants emphasised this reflective time was powerful in order to allow teams to invest in new ways of working. Notably, the intervention period was 2 years in duration, much longer than most quality improvement projects. This provided adequate time for teams to reflect, learn and adjust, and required significant commitment from the senior leadership of the hospital.

The delivery of the intervention as described was not without challenges. First, as with many complex outcome indicators, hospital access to the publicly reported 30-day RSMR for patients with AMI from CMS lagged by approximately 18 months, limiting usefulness for improvement efforts in real time. In response, while the overarching LSL study design used 30-day RSMR as a primary outcome, we worked with each coalition to identify a meaningful and feasible measure of AMI mortality in their context to drive problem solving, including in-hospital mortality for many, and risk adjustment for some that had access to proprietary software. Second, several hospitals underwent large-scale transitions (ie, changes in ownership or leadership) that generated uncertainty among coalition members. In response, for teams facing major barriers and transitions, we emphasised and revisited workshop curriculum related to engaging key stakeholders, creating (and recreating) shared commitment to the objective and aligning with organisational events and priorities with attention to identification of concrete action plans to promote progress despite turbulent context. Third, at the start of the intervention, we experienced mixed buy-in from senior clinical staff on the relevance of organisational culture (and especially the domain of psychological safety). In response, we invested in continuous synthesis and communication of the scientific evidence base linking organisational culture to clinical outcomes, facilitated conversations about organisational culture that 
were grounded in real-time feedback of quantitative measures of each hospital's' culture and engaged with friction openly in an attempt to model engagement of diverse perspectives and productive conflict.

Several limitations in the design and implementation of the intervention are worth noting. First, this is the first (to our knowledge) prospective intervention to attempt to shift organisational culture across diverse sites as a driver of complex patient outcome, we designed a large and resource-intensive model of intervention that we believed had the best chance of showing impact. The cost of replication of this intervention may be prohibitive for many hospital networks. Second, our mixed methods longitudinal evaluation was not designed to show which components of the intervention were most effective. Nevertheless, detailed, rapid participant feedback in the form of workshop/meeting evaluation surveys helped us tailor along the way. Third, although the fidelity checklists were highly valued by the intervention facilitation team, the study was not designed to measure fidelity in a nuanced way as it relates to variation in uptake/outcomes across sites. Yet extensive qualitative data gathered through interviews and observations indicate similar receptivity/experience with the intervention. In addition, we paid close attention to identifying core milestones/objectives for each component of the intervention. Finally, selection bias may have occurred as a result of our sampling approach. However, there was a high degree of receptivity across all levels of hospitals (from the senior executive offices to front-line caregivers), and all but two hospitals that we approached enrolled and remained active for the entire study period. Because we relied on a carefully selected network, it is not clear how recruitment and retention would have fared in a broader recruitment effort.

\section{CONCLUSION}

In summary, LSL is, to our knowledge, the first successful longitudinal intervention to prospectively change aspects of hospital organisational culture associated with patient outcomes. This in-depth, practical description of the development and delivery of the intervention may be useful for healthcare practitioners seeking to promote organisational culture change in their own contexts, researchers seeking to compare the results of the intervention with other leadership development and organisational culture change efforts and healthcare professionals committed to understanding complex interventions across healthcare settings.

\section{Twitter Erika Linnander @erika.linnander and Leslie Curry} @lesliecyale

Contributors EL and ZMN conceived and led the intervention. EL and LC conceived and drafted the manuscript. KB participated in the delivery of the intervention. All authors made substantive contributions to the manuscript and reviewed and approved the final submission.
Funding This study was funded by The Medicines Company. Competing interests None declared.

Patient consent for publication Not required.

Ethics approval All research procedures were approved by the Human Investigation Committee at Yale University and determined to be exempt under Federal Regulation 45 CFR 46.101(b)(2).

Provenance and peer review Not commissioned; externally peer reviewed.

Data availability statement Data sharing is not applicable as no data sets were generated and/or analysed for this study.

Open access This is an open access article distributed in accordance with the Creative Commons Attribution Non Commercial (CC BY-NC 4.0) license, which permits others to distribute, remix, adapt, build upon this work noncommercially, and license their derivative works on different terms, provided the original work is properly cited, appropriate credit is given, any changes made indicated, and the use is noncommercial. See: http://creativecommons.org/licenses/by-nc/4. $0 /$.

\section{ORCID iDs}

Erika Linnander http://orcid.org/0000-0002-3417-1049

Leslie Curry http://orcid.org/0000-0002-3419-4654

\section{REFERENCES}

1 Curry LA, Spatz E, Cherlin E, et al. What distinguishes topperforming hospitals in acute myocardial infarction mortality rates? A qualitative study. Ann Intern Med 2011;154:384-90.

2 McFadden KL, Stock GN, Gowen CR. Leadership, safety climate, and continuous quality improvement: impact on process quality and patient safety. Health Care Manage Rev $2015 ; 40: 24-34$.

3 Singer S, Lin S, Falwell A, et al. Relationship of safety climate and safety performance in hospitals. Health Serv Res 2009;44:399-421.

4 Taylor N, Clay-Williams R, Hogden E, et al. High performing hospitals: a qualitative systematic review of associated factors and practical strategies for improvement. BMC Health Serv Res $2015 ; 15: 244$.

5 Curry LA, Linnander EL, Brewster AL, et al. Organizational culture change in U.S. hospitals: a mixed methods longitudinal intervention study. Implement Sci 2015;10:29.

6 Curry LA, Brault MA, Linnander EL, et al. Influencing organisational culture to improve hospital performance in care of patients with acute myocardial infarction: a mixed-methods intervention study. BMJ Qual Saf 2018;27:207-17.

7 Kotter JP. Leading change. Boston, MA: Harvard Business Review Press, 1996.

8 Bradley EH, Brewster AL, McNatt Z, et al. How guiding coalitions promote positive culture change in hospitals: a longitudinal mixed methods interventional study. BMJ Qual Saf 2018;27:218-25.

9 Curry LA, Brault MA, Cherlin E, et al. Promoting integration of pharmacy expertise in care of hospitalized patients with acute myocardial infarction. Am J Health Syst Pharm 2018;75:962-72.

10 Flieger SP, Spatz E, Cherlin EJ, et al. Quality improvement initiatives to reduce mortality: an opportunity to engage palliative care and improve advance care planning. Am J Hosp Palliat Care 2019;36:97-104.

11 Carroll C, Patterson M, Wood S, et al. A conceptual framework for implementation fidelity. Implement Sci 2007;2:40. 
12 Craig P, Dieppe P, Macintyre S, et al. Developing and evaluating complex interventions: the new medical Research Council guidance. BMJ 2008;337:a1655.

13 Kearney MH, Simonelli MC. Intervention fidelity: lessons learned from an unsuccessful pilot study. Appl Nurs Res 2006;19:163-6.

14 Curry LA, Krumholz HM, O'Cathain A, et al. Mixed methods in biomedical and health services research. Circ Cardiovasc Qual Outcomes 2013;6:119-23.

15 Bradley EH, Brewster AL, Fosburgh H, et al. Development and psychometric properties of a scale to measure Hospital organizational culture for cardiovascular care. Circ Cardiovasc Qual Outcomes 2017;10.

16 Bradley EH, Curry LA, Spatz ES, et al. Hospital strategies for reducing risk-standardized mortality rates in acute myocardial infarction. Ann Intern Med 2012;156:618-26.

17 Bradley EH, Curry LA, Taylor LA, et al. A model for scale up of family health innovations in low-income and middle-income settings: a mixed methods study. BMJ Open 2012;2:e000987.

18 Friedman RA, Podolny J. Differentiation of boundary spanning roles: labor negotiations and implications for role conflict. Adm Sci Q 1992;37:28-47.

19 Curry LA, Ayedun AA, Cherlin EJ, et al. Leadership development in complex health systems: a qualitative study. BMJ Open 2020;10:e035797.

20 Patton MQ. Purposeful sampling. In: Patton MQ, ed. Qualitative research and evaluation methods. 230. 3th edn. Thousand Oaks, CA: Sage Publications, 2002.

21 Greenhalgh T, Robert G, Macfarlane F, et al. Diffusion of innovations in service organizations: systematic review and recommendations. Milbank Q 2004;82:581-629.

22 Schein EH. Organizational culture and leadership. 4th edn. San Francisco: Jossey-Bass, 2010.
23 Bradley EH, Nembhard I, Taylor L, et al. Leadersip and management: a framework for action. In: Burns L, Weiner B, eds. Shortell and Kaluzny's Health Care Management: Organization Design and Behavior. New York: Delmar Cengage Learning, 2019: 32-55.

24 Rizzo JR, House RJ, Lirtzman SI. Role conflict and ambiguity in complex organizations. Adm Sci Q 1970;15:150-62.

25 Schweiger DM, Sandberg WR. The utilization of individual capabilities in group approaches to strategic decision-making. Strategic Management Journal 1989;10:31-43.

26 Mello JA. Improving individual member accountability in small work group settings. Journal of Management Education 1993;17:253-9.

27 Schulz-Hardt S, Jochims M, Frey D. Productive conflict in group decision making: genuine and contrived dissent as strategies to counteract biased information seeking. Organ Behav Hum Decis Process 2002;88:563-86.

28 Alderfer CP. The practice of organizational diagnosis. New York: Oxford University Press, 2011.

29 Berg DN. Levels of analysis: diagnosis \& intervention. Available: http://csms.org/wp-content/uploads/2015/04/LevelsOrganizational-Analysis.pdf [Accessed 7 Dec 2016].

30 Jaques E. In praise of hierarchy. Harv Bus Rev 1990;68:127-33.

31 Ronay R, Greenaway K, Anicich EM, et al. The path to glory is paved with hierarchy: when hierarchical differentiation increases group effectiveness. Psychol Sci 2012;23:669-77.

32 Bradley EH, Curry LA, Ramanadhan S, et al. Research in action: using positive deviance to improve quality of health care. Implement Sci 2009;4:25.

33 Marsh DR, Schroeder DG, Dearden KA, et al. The power of positive deviance. BMJ 2004;329:1177-9. 